Session 2615

\title{
The Use of "Superclients" in a Civil Engineering Capstone Design Class
}

\author{
Wilfrid A. Nixon \\ Iowa Institute of Hydraulic Research \\ And \\ Department of Civil and Environmental Engineering \\ University of Iowa \\ Iowa City, IA 52242-1585
}

\begin{abstract}
The capstone design class in Civil and Environmental Engineering at the University of Iowa is a three-semester hour class, with an enrollment of between 30 and 50 students in recent years. In the ideal, this class should offer students the opportunity to demonstrate that their education has brought them to a point at which they can begin to contribute effectively in the workplace. However, finding a project that is sufficiently challenging presents a perennial challenge.
\end{abstract}

To address this issue, the class was changed in 1997 to allow local civil engineers to provide projects for the students. These local civil engineers served as "superclients" for the students, who worked on their projects in groups of five or six. Students were able to visit project sites and "kick the tires," which substantially reduced student complaints that projects were not realistic. They also had the experience of interacting with clients who were not faculty.

While the approach creates some logistic difficulties, the benefits are substantial. The paper describes both, and reports on the problems and successes of this particular approach.

\section{INTRODUCTION}

The capstone design class is a critically important part of any engineering curriculum. In the ideal, it offers students the opportunity to demonstrate that their educational experience has not been merely a disjoint collection of classes with only tenuous connections, but rather a well-founded continuum that has brought them to the point from which they can begin to be effective in the workplace. However, a perennial challenge for capstone classes is finding a project that is sufficiently challenging to present a complete test of a student's education, yet also can be completed within a single semester (or at most, within two semesters). 
In the civil engineering program at the University of Iowa, the capstone design class (53:084 Project Design and Management in Civil and Environmental Engineering) has been a one semester, three credit hour class offered once a year in the spring semester. Students have typically worked in groups of between four and eight students on a single project whose scope was developed by faculty. In recent years, enrollment for the class has been between 30 and 50 students.

In the Fall of 1997, it was decided that a different approach was needed. This was precipitated by three factors. First, there was a feeling that the course, and in particular the projects, were getting stale. This may reflect unease among the faculty regarding their ability to develop meaningful projects. In previous years, a number of students had commented in class evaluations that they did not feel the projects were realistic. Second, recent experience in the Mechanical Engineering department in the College of

Engineering showed that it was not only possible to incorporate real world projects into the curriculum, but it could be a highly effective learning experience for students. Third, a number of practicing civil engineers, especially contacts through the Iowa Section of ASCE, had expressed interest in being involved in projects with students. These factors combined to allow for a different approach in project development for the class (53:084), and this new approach (described in detail below) has been used in the three most recent offerings of the class (Spring 1998, Spring 1999, and Spring 2000).

In developing the new class, it was felt that a major benefit would be the interaction between students and practicing engineers. This was seen as an opportunity to extend the relationship between instructor and students that is so critical to a successful capstone design experience ${ }^{1}$. In addition, by providing a "real" client (as opposed to "just" a faculty member) it was hoped that the students would be more inspired, and thus the experience might come somewhat closer to the optimal ${ }^{2}$.

The purpose of this paper is to describe the "superclient" method of project development and to report on the successes and problems of this approach.

\section{CLASS STRUCTURE}

It was decided that the class should begin somewhat like a more regular class, with three classroom meetings a week. This allowed for introduction of basic material that would allow the students to function more effectively while working on their projects. Thus for the first six weeks of the semester the class appeared to be somewhat similar to a regular class. However, by week four students had been formed into their design groups (see below for the process) and began their work as a team. At that time, they had also been assigned their projects, and the RFPs (Requests for Proposals) had been issued for their projects.

Proposals were due on Monday of week 8 of the semester. Students then had to perform a review of another team's proposal (termed a "red team" review) by Friday of that week. This review served as a mid-term exam. Immediately after week 8, the University has

"Proceedings of the 2001 American Society for Engineering Education Annual Conference \& Exposition Copyright (C) 2001, American Society for Engineering Education” 
Spring Break, and upon resumption of the semester, students were required to give a presentation of their proposals. In the second half of the class (weeks 9 through 15) there were no formal class meetings, but each group had to provide regular feedback to the instructor and the superclient, either through memos or meetings.

Students had to give their final project presentations in the middle of week 15 of the semester, and their final reports were due by close of business on Friday of that week.

Students' grades were based upon six activities: the project proposal, the red team review, the proposal presentation, the final project presentation, the final project report, and weekly progress reports. The first five were graded as a group, while the sixth category was graded individually. In addition, $10 \%$ of the final grade was reserved to the Professor for "Professional Conduct." This was crucial in allowing different team members to receive different grades.

The formation of project groups, and the assignment of projects to each group, is a critical part of the class. To help students work in groups, they take the Myers-Briggs Personality Test during the first four weeks of the class. A certified tester administers the test and explains to the students how people of differing personality types interact with each other. This gives the students some understanding of the different approaches that they may each take to the project, and suggests ways for them to accept and value these different approaches.

Students are allowed to suggest their own project teams, and can also list in priority order the projects that they would like to tackle. However, the instructor specifically reserves the right to adjust teams and assign projects.

A perennial concern of students is that not all members of a group will contribute equally. Weekly memos are required from all students in the class, and this allows the instructor some oversight into the individual efforts of team members, but this alone does not ensure either equal effort or appropriate reward. In regard to the latter, students are given the opportunity after every group exercise (project proposal, red team review, proposal presentation, final project presentation, final project report) to evaluate the relative efforts of themselves and their group members. This is done by use of a simple form that allows them to assign points according to effort for each team member on that assignment. If a student submits no form by the due date, then an equal distribution of effort is assumed.

About half the teams never made use of these forms, having decided that they would ensure in and of themselves that effort was equally expended. In some cases, however, use of the forms showed clearly that some team members consistently failed to pull their weight on the team, and in such cases, these team members were assigned lower grades than their colleagues.

"Proceedings of the 2001 American Society for Engineering Education Annual Conference \& Exposition Copyright (C 2001, American Society for Engineering Education" 


\section{SUPERCLIENT INVOLVEMENT}

The instructor for the class sends out an invitation in December to a list of local civil engineers who have, in one way or another, expressed interest in the civil engineering program at the University of Iowa. Many of these are contacts made through the Iowa Section of ASCE, but others have given seminars to the undergraduates or are alumni of the program. This invitation asks them to submit projects that have not yet been designed, but that are real, and "in the works," in the sense of being under consideration for design in the next one to three years.

In early planning of this approach it rapidly became apparent that projects that had already been designed could not be used. Many of our seniors work with local engineers, and existing solutions would have been "discovered" by enthusiastic students, thus diminishing substantially the value of such real world projects.

At this stage of the process, all that was requested of the potential superclients was a brief description of the project. Table 1 (in the Appendix) shows one such description (from the 1999 class). These project descriptions are provided to students in the first week of class. The instructor uses this description to develop an RFP for the project. The RFP, after being reviewed by the superclient, is presented to the project teams in week 4 of the class. By this stage, teams have already been formed and projects assigned. The RFP is presented in two parts. The first part is common to all projects and deals with the format of the proposal and similar issues. This is shown in Table 2 of the Appendix.

The second part of the RFP, referred to in section 2 of the general RFP requirements, is specific to the project and sets out in detail the needs of the particular project. An example of such an RFP for the project described in Table 1 is shown in Table 3 in the Appendix.

The RFP serves not only as the basis for the team proposal, but also as a blueprint for the work required on the project itself. Often this will be the first time that students have worked from an RFP, and many find it difficult to adjust to this. However, they are free to seek guidance from the instructor and the superclient.

It is worth noting that a specific requirement is included in each RFP that the instructor must be informed whenever the team contacts the superclient. The intent here is to avoid the superclient being badgered by students who want all the answers without having to do any work. To date, none of the superclients have expressed concerns over this, but it needs to be monitored in some fashion, and the requirement of this notice seems to work well in this regard.

Once student teams have received the RFPs they also are required to submit weekly memos to the instructor (also termed the client) and the superclient. The instructor can then interact with the superclient to ensure that adequate progress is being made.

"Proceedings of the 2001 American Society for Engineering Education Annual Conference \& Exposition Copyright @ 2001, American Society for Engineering Education" 
Superclients receive copies of the proposal and final report, and their input on the grading of these is sought. However, to keep the burden on the superclient minimal, no formal grading of these is required from the superclient. Typically they give substantial oral feedback to their project teams in the course of the project and this is probably more valuable than a written grading of their proposal or final report.

Superclients also attend the proposal and final project presentations, and are always given the opportunity to ask the first questions at these presentations. This is where the value of the superclients is perhaps most obvious. One particular example may serve to illustrate this. At proposal presentations in 2000, two of the projects had a local City Engineer as the superclient. The City Engineer asked both project teams after their proposal presentation "Why should I hire you rather than somebody else?" Students protested that such a question was unfair to which the City Engineer replied "But I ask all my proposal presenters the same question?" The City Engineer had a credibility in asking such a question that faculty could not have, and made the experience considerably more realistic (and stressful!) for the students.

\section{CHALLENGES AND BENEFITS}

A major issue with this approach to a capstone class is ensuring an adequate supply of projects and superclients. Although the class is only in its fourth year in this format this has not, yet, been an issue. Some superclients are happy to be involved each year, and relish the chance to work with the students. Others seem happy to submit a single project one year and then take a year "off." Thus at present this does not appear to be a concern. Simply asking for help has produced a good response.

Another issue has been accessibility of the superclient for the students. In one project, where the superclient was not based locally in Iowa, this was a concern. Accordingly, the instructor now only approaches local superclients, and makes it clear in the invitation that a certain degree of access for students is required.

A third concern is balance between projects. Clearly, when real world projects are used not all projects will be equally challenging. To a degree this can be handled by adjusting the scope of a project (reducing the scope of particularly challenging projects, for example) but it will always be the case that some projects will require more effort than others. Students have not yet expressed concern over this, perhaps because such disparities have not been large. Also, the red team reviews may help in this regard, because they show students that other projects do have substantial challenges.

A final issue is the timing of the whole class. More than half the semester is over before students have presented their proposals, and there is certainly the potential that there may not be enough lead time available to students to complete the project. In fact, it appears that the RFP process is very helpful to the students in that it requires a very clear enumeration of the tasks that have to be accomplished to achieve the end goal of the project. Teams are required to produce a Gantt chart for their projects and to identify the

"Proceedings of the 2001 American Society for Engineering Education Annual Conference \& Exposition Copyright @ 2001, American Society for Engineering Education" 
critical path on the chart. This makes it abundantly clear that they cannot allow things to slip, and seems to impose a discipline that in other circumstances may not be evident.

The discipline of project planning may not, however, be sufficient for all projects. Accordingly, it is critical in choosing the projects that care is taken by the instructor and the superclients to ensure that all needed materials are available to the students in a timely manner. To date, all project teams have met with their superclient prior to the submission of the proposal, and at that time the superclients have shared a lot of information (more than would be available in the typical RFP process) with the teams. This process has meant that to date, no team has experienced insuperable difficulties in meeting class deadlines.

That is not to say that more time would not be of benefit. The Civil and Environmental Engineering department at the University of Iowa is currently considering an elective two-course sequence that would focus on "large" civil engineering projects, and would allow for lengthier and more detailed design projects to be addressed. This sequence is still in the planning stage.

The benefits of the superclient approach are substantial. First and foremost, students work on real projects and with practicing engineers. The issue of whether a project is made-up is no longer a concern. Closely related to this is the fact that students know their work is being scrutinized by someone who does design on a daily basis, and who can both help them substantially, and also see very quickly if they are not applying themselves appropriately.

It often comes as a surprise to the students that their superclients stress the communications aspect of the projects so strongly. They do not expect to be told that the presentation and the final report are very important, yet this message comes through clearly. Presentations and reports have typically been part of capstone classes, but having their value reinforced by practicing engineers is a definite benefit to the students.

Finally, students agree that the superclient process is as close as they can reasonably come to a real design experience in a classroom setting. That is a significant part of what a capstone class should achieve, and if the superclients make that a reality, then they have been a success.

\section{EVALUATION}

No comparative evaluation between the "superclient" approach and the previous offering of the class was made, and indeed such a comparison is not strictly possible because the two course approaches were never offered in parallel. However, students have been asked to comment on the "superclient" approach, and most comments have been favorable. Many comments stressed how much students valued being involved with "real" engineers and projects (as opposed, perhaps, to "unreal" faculty?). 
The instructor has also asked regularly for informal feedback from the superclients. Most have reported enjoying the experience, which is further evidenced by more than $80 \%$ of superclients volunteering more than once to assist in the course. One identified area of deficiency is on the topic of estimating, and steps are being taken during the Spring 2001 course offering to address this deficiency for the students.

The course has also been examined by the department's Advisory Board (some of the members of the board have served as superclients) and they have encouraged the continuation of this form of capstone class. Based on these various (albeit informal) evaluations, the department expects to offer the course in the current form in the future.

\section{CONCLUSIONS}

The capstone design class at the University of Iowa was changed in 1998 to include real world projects provided by superclients (practicing engineers) who stay involved with the student teams throughout the course of the project. Students develop proposals on the basis of an RFP and from these develop a final report and presentation, providing weekly feedback through memos and meetings to the superclients.

The involvement of practicing engineers so directly with the capstone experience proves to be very beneficial to students in a number of ways, and appears to engage their enthusiasm for their projects very strongly. The approach is judged to be very successful and will be continued.

\section{BIBLIOGRAPHY}

1: Catalano, G. D., 1994. Engineering Design: A Partnership Approach, Journal of Engineering Education, Volume 83, No. 2, pages 130-134.

2: Marin, J. A., Armstrong, J. E. Jr., and Kays, J. L., 1999. Elements of an Optimal Capstone Design Experience, Journal of Engineering Education, Volume 88, No. 1, pages 19-22.

\section{WILFRID NIXON}

Wilfrid Nixon is a Professor of Civil and Environmental Engineering at the University of Iowa and a research engineer at the Iowa Institute of Hydraulic Research. Dr. Nixon is a Professional Engineer in the State of Iowa, and also serves as a Director of the Iowa Section of ASCE. Dr. Nixon received a B. A. in Engineering from Cambridge University, England in 1981, and a Ph. D. in Engineering from Cambridge University in 1985.

\section{ACKNOWLEDGEMENTS}

The success of this class is strongly dependent on the involvement and hard work of the superclients, and this is gratefully acknowledged. In addition, the author acknowledges the strong support of three colleagues (Professors Ettema, Holly, and Stoner) who provided guidance, coffee, and other beverages to aid the course development. 


\section{APPENDIX}

The following materials, listed in tables 1 through 3 , are taken directly from class materials provided to students. In this case the project was from the Spring 1999 offering of the class. Table 1 shows the initial project description that students receive very early in the class. It is reproduced in the project specific RFP (Table 3), and such reproduction is typical of most projects. Table 2 shows the general RFP material that all project teams receive, and Table 3 shows the specific RFP materials for this particular project.

\section{Table 1: Project Description for Capstone Class, 1999 Wilton Sludge Handling and Disposal Design}

The new Federal Sludge Regulations, referred to as the 503 regs were first published in the Federal Code as 40CFR Part 503 on February 19, 1993. These Federal Regulations are now part of the city's NPDES permit. These regulations control the treatment and final disposal of municipal sludge. They set standards for pathogen treatment, vector treatment, detention, and sludge application methods.

The existing 26-ft. diameter spirogester has a maximum sludge storage capacity of 79,000 gallons. This is a cold non-mixed sludge treatment system. The sludge from it is not thoroughly broken down and stabilized. Because of this, it does not meet the pathogen reduction or vector attraction standards of 503 regulations.

The existing treatment facilities have two sludge drying beds. Currently about $18-24 \%$ of sludge is dried on drying beds, with the remainder liquid hauled and land applied.

The plant itself is a trickling filter plant with a rock trickling filter and a plastic media filter tower. Each filter has it's own final clarifier. The spirogester functions as both a primary clarifier and sludge treatment unit. The design team must develop a design that addresses all shortcomings of the current plant, and brings the facility into compliance with Federal Sludge Regulations.

One copy of the 1964 blueprints and three sets of the 1987 plans are available for use by the team. Records of plant operation will also be available.

\section{Table 2: General RFP for Capstone Class, 1999 \\ 1. PROJECT PROBLEM STATEMENTS}

1.1 Six different projects are being handled by eight different teams formed in the 53:084 Class, for Spring Semester 1999. Groups will receive specific instructions for their project in a separate packet. This document includes general instructions that are common to all projects. Failure to follow the instructions set forth both in this document and in the specific project RFP documents will result in a negative evaluation of the Proposal and/or Final Design.

1.2 Proposals will be due on or before 5.00 p.m., Central Standard Time, March 8, 1999, delivered to Room 2130 Seaman's Center, The University of Iowa. Five complete copies of each proposal must be submitted.

Project Managers, assisted by Team Members as needed, will present the proposals on March 22 and 24, 1999, during the class period of the course 53:084 in room 22 Schaeffer Hall. A 10minute presentation will be allowed.

Final Report presentations will be made during the week of May 3 to 7, 1999, either during the class period of the course 53:084 in room 22 Schaeffer Hall, or at another time and place to be announced. A 20 minute presentation will be allowed.

Final Design Reports will be due on or before 5:00 p.m., Central Standard Time, May 7, 1999, delivered to Room 2130 Seaman's Center, The University of Iowa. Five complete copies of each

"Proceedings of the 2001 American Society for Engineering Education Annual Conference \& Exposition Copyright (C 2001, American Society for Engineering Education" 
Final Design Report must be submitted.

\section{DESIGN REQUIREMENTS}

2.1 Specific design requirements are set forth in a separate document, as indicated in 1.1 above. Teams should refer to the design requirements for their individual project.

\section{PROPOSAL REQUIREMENTS}

3.1 The proposal as submitted to the Client must contain the following information:

3.1.1 A cover page with the name of the engineering firm and the names of the design team members.

3.1.2 A letter of intent signed by the designated project manager.

3.1.3 A statement of the design objectives and the major problems likely to be encountered in the design process.

3.1.4 A list of the work tasks to be accomplished during the design-data collection, design, evaluation, report preparation, and presentation segments of the projects.

3.1.5 A critical path diagram or Gantt chart identifying the procedure and time schedule of the project tasks.

3.1.6 A table assigning work tasks to specific team members.

3.1.7 A detailed budget for the design study, by task, estimating work hours and cost.

3.1.8 A budget summary listing the total expected personnel, direct, and indirect costs associated with the project.

3.1.9 A short management plan and organization chart.

3.1.10 Brief (1 page) resumes for each project team member in a standard format.

3.2 Any external consultants used on the project must have the approval of the Client or the Client's designated representative, with the exception of Faculty Consultants as listed in the Individual Project RFP documents. When Faculty Consultants are used, their contribution must be appropriately acknowledged. It is estimated that 3 - 4 person months of time will be required to perform this project.

3.3 Due respect for the English language and/or its American derivative must be shown in the proposal and all reports to the Client.

\section{Table 3: Specific RFP for Capstone Class, 1999 \\ 1. PROJECT PROBLEM STATEMENT}

1.1 This project is being handled by Team Delta formed in the 53:084 Class, for Spring Semester 1999. Groups will receive general RFP instructions in a separate packet. This document provides specific instructions for this project. Failure to follow the instructions set forth both in this document and in the general project RFP documents will result in a negative evaluation of the Proposal and/or Final Design.

1.2 The new Federal Sludge Regulations, referred to as the 503 regs were first published in the Federal Code as 40CFR Part 503 on February 19, 1993. These Federal Regulations are now part of the city's NPDES permit. These regulations control the treatment and final disposal of municipal sludge. They set standards for pathogen treatment, vector treatment, detention, and sludge application methods.

The existing 26-ft. diameter spirogester has a maximum sludge storage capacity of 79,000 gallons. This is a cold non-mixed sludge treatment system. The sludge from it is not thoroughly broken down and stabilized. Because of this, it does not meet the pathogen reduction or vector attraction standards of 503 regulations. The existing treatment facilities have two sludge drying beds. Currently about $18-24 \%$ of sludge is dried on drying beds, with the remainder liquid hauled and land applied.

The plant itself is a trickling filter plant with a rock trickling filter and a plastic media filter tower. Each filter has it's own final clarifier. The spirogester functions as both a primary clarifier and sludge treatment unit. The design team must develop a design that addresses all shortcomings of the current plant, and brings the facility into compliance with Federal Sludge Regulations.

One copy of the 1964 blueprints and three sets of the 1987 plans are available for use by the team. Records of plant operation will also be available.

"Proceedings of the 2001 American Society for Engineering Education Annual Conference \& Exposition Copyright (C) 2001, American Society for Engineering Education" 


\section{DESIGN REQUIREMENTS}

2.1 The design year for the new facility is to be taken as the year 2019 .

2.2 The design life of any structure shall be fifty years.

2.3 The scope of this design project includes but is not limited to the following:

2.3.1 Conduct a kickoff meeting with the client to solicit input, gather available data and information, and perform field reconnaissance. Additional progress-review meetings will be conducted on a regular basis. Weekly progress reports are required.

2.3.2 Ensure the designs meet the requirements of the City of Wilton.

2.3.3 Ensure that the designs meet the requirements of the Iowa Department of Natural resources (IDNR), and the Environmental protection Agency (EPA). In addition, ensure that the designs meet the requirements of the 503 regulations.

2.3.4 Prepare a set of at least three design alternatives for at least three design options. Preliminary design drawings and cost estimates should be prepared.

2.3.5 Provide a complete impact assessment of the alternative designs, that completely weighs the benefits and costs including capital investment, operational costs and serviceability. Secondary and tertiary effects such as pollution, and aesthetics should also be considered.

2.3.6 Develop a selection criteria for choosing an appropriate design for implementation.

2.3.7 Prepare preliminary site plans and conceptual drawings of recommended alternatives.

2.3.8 Prepare cost estimates for alternatives and recommended design.

2.3.9 Develop construction contract breakdown based on types of work and schedule requirements.

2.3.10 Prepare overall project schedule.

2.3.11 Prepare a Final Design Report as described in General Requirements section 1.2

\section{PROPOSAL REQUIREMENTS}

3.1 The proposal requirements are set forth in the General Requirements in Section 3.

3.2 Any external consultants used on the project must have the approval of the Client or the Client's designated representative, with the exception of Faculty Consultants as listed in the Individual Project RFP documents. When Faculty Consultants are used, their contribution must be appropriately acknowledged. Any contact with the "superclient" must be reported by the team to the Client within one working day. It is estimated that 3 - 4 person months of time will be required to perform this project.

"Proceedings of the 2001 American Society for Engineering Education Annual Conference \& Exposition Copyright (C 2001, American Society for Engineering Education" 